\title{
A NEW FRAME FOR THE POSITIONING OF PATIENTS FOR SURGERY OF THE BACK
}

\section{IAIN M MaCKAY, M.D, F A C A.*}

THE Positioning of patients for surgery of the back, especially of the spinal column, is a problem of equal importance to both surgeon and anaesthetist. While the primary consideration of each is different it is obvious that for the ultimate benefit of the patient their viewpoints must coincide closely.

There can be no doubt that the best possible operating conditions contribute to the success of any operation and to the recovery of the patient. However, it is most important that these conditions should not be achieved by imposing upon the patient other conditions unnecessarly disturbing to his physiological integrity.

Although for some operative procedures on the spinal column and related structures the patient may be placed in the lateral position or occasionally in the sitting position, the use of the prone position is favoured by most surgeons. For optimal operating conditions, particularly for surgery involving the lumbosacral vertebrae, varıous degrees of flexıon or of extension of the back must be achieved It is also desirable to be able to alter the position if the procedure should require it for best results. Unfortunately, the prone position of the anaesthetized patient, particularly the obese individual, on the ordinary operating table tends to diminish respiratory excursion or even to cause actual respiratory obstruction because pressure of the abdomen prevents proper functioning of the diaphragm Normally responsible for roughly 60 per cent of the lungs' expansion, the diaphragm is even more important in the prone anaesthetzed patient and interference with its excursion leads to both respiratory and cardiovascular complications

Inadequate respuration leads inevitably to anoxia and carbon dioxide retention, and, because of an increased blood pressure, may cause excessive blood loss at the operative site More important, perhaps, in contributing to blood loss and congestion in the surgical field, is the compression of the great veins of the abdomen, resulting in back pressure and in dimmished venous return to the heart

During the past year we have used in a number of cases a new positioning frame whuch has helped to solve our pıimary problems (Fig. 1). It consists essentially of two curved, heavily padded longitudinally placed metal bars, hinged at their mid point so that the height of the frame's apex and the degree of curve may be readily adjusted These curved bolster bars are laterally adjustable by manual positioning and, once set, may be locked The degree of curve is controlled by a longitudinally and centrally located screw which is operated from the foot of the table by a three-foot handle. This frame, if properly used, allows complete freedom of the abdomen It allows a great range of positioning of the spinal column varying from extreme flexion to hyperextension it is sturdy, cheap, and simple and has achieved some degree of popularity with the ortho-

"Department of Anaesthesıa, University of Toronto, and Toronto General Hospital

Received for publication May 9, 1956 


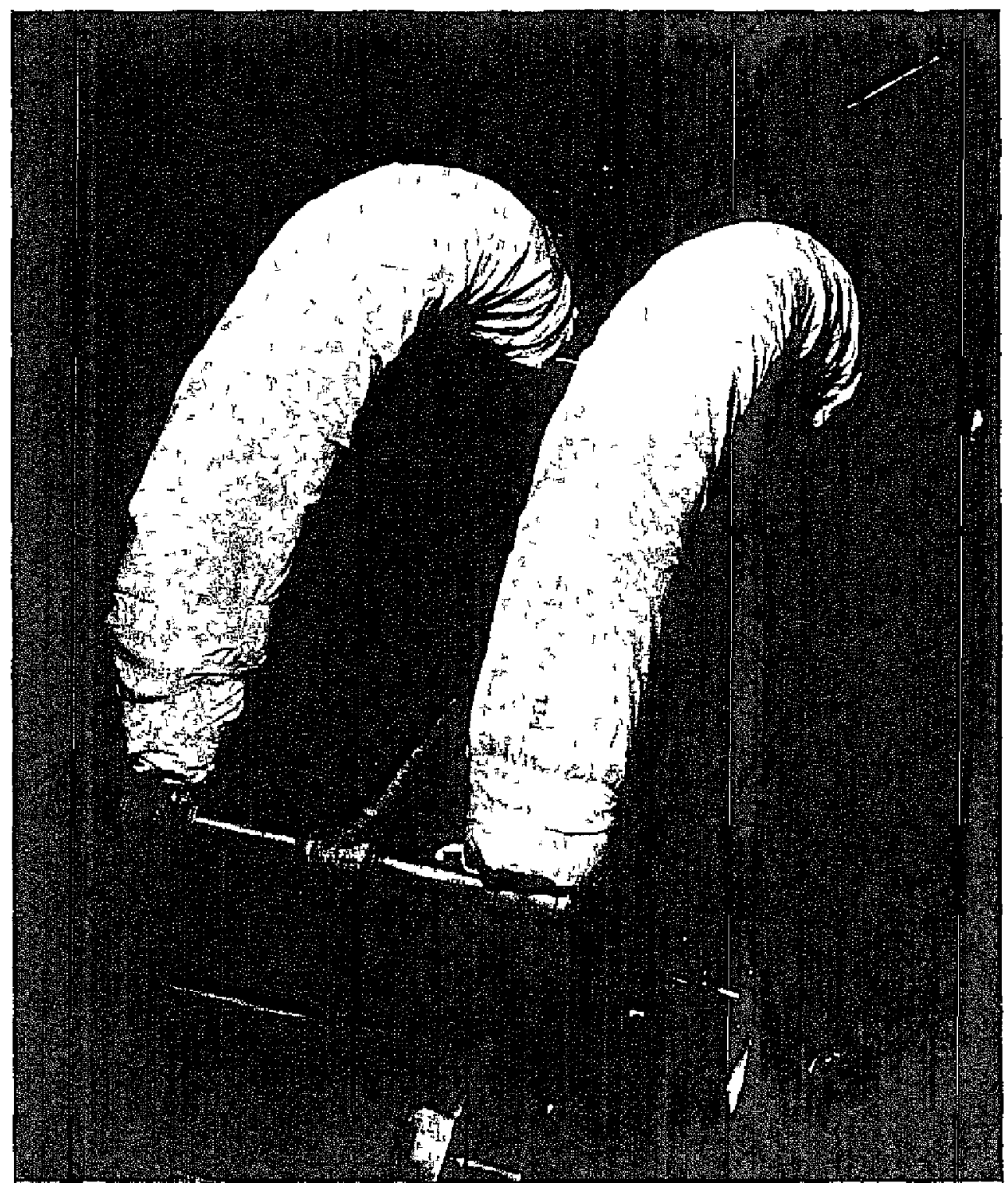

Figure 1 Frame in pusition on operitung table

pdedic surgeons and neurosurgeons in the Toronto General Hospital However, like any other piece of apparatus, it can be mssused Careful positioning of the patient is stili essental

If the bolster bars are placed too close together they mey themselves obstruct the abdomen If they are placed too tar apart the patient may fall between them They are best adjusted to support the patient at the anterior superior spines of the ilium and in the mid-clavicular line in the thoiacic region The bolster bars are thus often in the best position when not: paluallel, but somewhat closer together at the upper end than at the lower

The patient should be so placed that the operative sitc is at the highest point of the curve If the position is any lower thin this, maximal fiexion cannot be 
obtaned This is partucularly true if the knees are allowed to rest on the table, in which case the pelvis remains tilted posteriorly The patient's arms should be extended above the head and should rest on the head of the table (Fig 2)

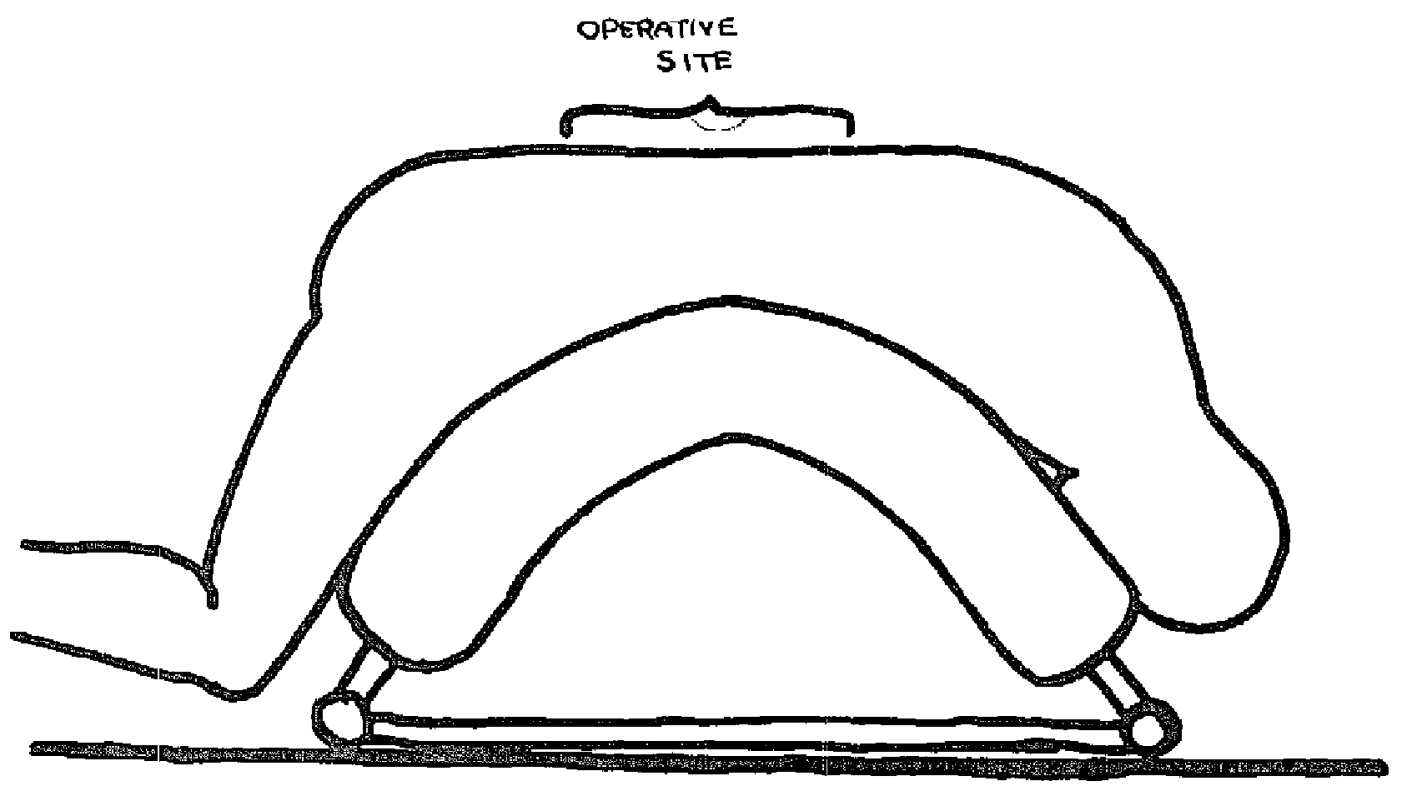

fy ICUhL 2 Pitient in postion on fo ime whth oper itive site over aper of frame

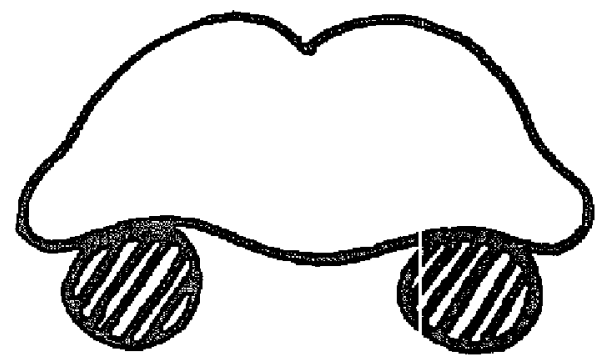

WONG

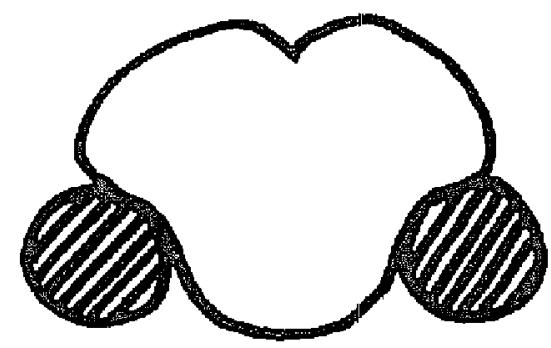

RIGHT

Ficums 3 Gross-section of obes patient rcsting on bolsters of frame 
Following lumbosacral fusion it is often desirable to transfer the patient to a Stryker Frame while he is still in the prone position. The bulk of our frame makes it impossible to fit it between the sections of a Stryker Frame. However, a canvas lifter has been devised which may be placed under the patient before operation.

The grossly obese individual with a pendulous abdomen is always a problem and must be so positioned on the frame that the abdomen hangs between the bolsters. If his fat is allowed to hang laterally and outside the frame his abdominal wall may act as a tight binder and produce both respiratory and venous obstruction (Fig. 3).

The frame may be used also for cases in which hyperextension is desirable and is more efficient than pillow bolsters. 